\title{
Development and Implementation of Modified Power Loss Detection Algorithm for Partial Shading in Real-time Photovoltaic System
}

\author{
D. Devaraj ${ }^{\text {a) }}$, J. Preetha Roselyn ${ }^{* b)}$, C. Nithya ${ }^{\text {b) }}$, C. Pranav Chandran ${ }^{\text {c) }}$, R. Venkatesan ${ }^{\text {d) }}$ \\ ${ }^{a}$ Department of EEE, Kalasalingam Academy of Research and Education, Srivilliputhur, India \\ ${ }^{b}$ Department of EEE, SRM Institute of Science and Technology, Chennai, India \\ ${ }^{c}$ Power System Engineering, University of Washington, Seattle, US \\ d Ocean Observation Systems, National Institute of Ocean Technology, Chennai, India
}

\begin{abstract}
The development of maximum power point tracking in solar photovoltaic system is important for obtaining the maximum power, which works satisfactorily when subjected to steady, undisturbed irradiation. Under real-time conditions, the solar panel does not always receive uniform irradiation owing to partial shading, thereby reducing the gross power output from the panel. The presence of partial shading is directly recognized by an occurrence of multiple local peaks in the performance characteristics of the solar panel. During partial shading, conventional maximum power point tracking algorithms fail to detect the global maximum power point, thus operating the panel at a much lower efficiency than desired. This study aimed to accurately detect the occurrence of partial shading condition in the solar Photovoltaic (PV) systems under different irradiation conditions and shading patterns. A partial shading detection mechanism is proposed based on power loss generated from a solar PV array without any sensors incorporated in the real-time platform. The proposed method is cost effective and accurate even under different seasonal and weather conditions, without any empirical constant and sensors. The proposed method is tested experimentally in real-time setup and the results are validated. The method provides a much higher accuracy than the current approximation and power loss method, and it does so by using the minimum number of variables. The proposed detection mechanism is compared with other existing methods in the Maximum Power Point Tracking (MPPT) algorithm, which proves the powerfulness of the algorithm. To test the performance of the proposed method, a real-time PV system with data acquisition using National Instruments LabVIEW is developed. Virtual Bench-8012 is used for data acquisition with a high precision along with intrinsic signal conditioning, and compact RIO-9081with a Field-Programmable Gate Array (FPGA) Virtex-5 LX150 is used for the MPPT algorithm implementation. The experimental results are also verified under different shading patterns and irradiation conditions for detecting the shading of the panel. Hence, it is shown that the detection algorithm has an efficiency of $97 \%$ in detecting the shading conditions of the panel.
\end{abstract}

Keywords: Solar Photovoltaic, Partial Shading, Global peak, Power loss method

\section{Introduction}

When the solar panels are not subjected to uniform irradiance throughout the panels, then the system is considered to have partial shading and hence reduction in output power. The nonshading conditions also result in reduction in the output power considering the inconsistency or variation of the irradiation throughout a day. Many authors in the literature have considered setting a threshold power to detect partial shading. In [1-8], the authors have considered the partial shading if the output power exceeds a certain threshold value or else, uniform irradiation is assumed which is not effective. Moreover, the basis on which the current and power threshold values are chosen is not indicated and hence, it is difficult to determine the exact value of the threshold given that no specific equations are involved. These methods scan the entire P-V curve even under uniform irradiation since they cannot differentiate the change in power under uniform irradiance or partial shading conditions. Hence, the converter will operate at a much lower power point rather than tracking the Maximum Power Point (MPP) and cannot compensate for the small shifts in MPP due to a dynamic change of insolation, temperature, and loading. To obtain the maximum output power, the Maximum Power Point Tracking algorithm should be able to discriminate between the global peaks, which indicate the maximum power, and the local peak, which arises during the partially shaded condition. If the threshold power is set very high, the algorithm cannot initiate a global peak search. On the other hand, if it is set very low, the algorithm gives a false trigger.
In [2], the author has assumed the threshold to be $10 \%$ to $20 \%$ of maximum power. Artificial Neural Network is used for partial shading detection and fault analysis of panels. Due to the number of cases considered by the ANN algorithm, it gives a real-time accuracy of $83 \%$ but the method become tedious in designing ANN algorithm under different system conditions. Likewise, threshold power is set to be $5 \%$ of the nominal power in [3]. Under the concept of normalized deviation of power presented in [4], threshold power, $\mathrm{P}_{\text {th }}$ is $15 \%$ but in [5], $10 \%$ is used. Hence, it is understood that the threshold value allotted is susceptible to change depending on various parameters including the array structure, geographical location etc.

The commonly used method is to set a threshold for both voltage and current [6-7] parameters but the changes in current depend greatly on the irradiation value. In [8], detection is done by measuring a voltage mismatch in the PV module. This requires the use of a voltage sensor in every module, which leads to high cost. In [9], the MPPT algorithm scans three specific points based on a predetermined duty cycle with current threshold, $\mathrm{I}_{\text {th }}$ as 0.2 and voltage threshold, $\mathrm{V}_{\text {th }}$ as 0.1 . Though this method holds good for most cases it needs tuning for some shading conditions. In [10], the detection is based on the state of shading where both current and voltage are kept as tuning parameters, but temperature affects both voltage at MPP, Vmpp and current at MPP, $I_{m p p}$ to a certain extent. Another method involves $P_{\text {th }}[11]$ which can be varied depending on weather conditions but dependency on temperature is not preferred since it requires frequent changing of the threshold. Ahmed et al [12] 
implemented a more reliable detection method by scanning the short circuit current and the MPP current to calculate irradiation. As we know, the relationship between current and irradiation is not always linear and hence current rapidly changes whenever irradiance, $G$ changes abruptly. In addition, two values of irradiances are calculated from the current values at 0.8 open circuit voltage of a single module, $\left(\mathrm{V}_{\mathrm{oc}}\right)$ and 0.8 open circuit voltage of a array ( $\mathrm{V}_{\text {oc_array }}$ ) at standard test conditions. The mismatch between two $G$ values and irradiation are plotted against each other and the threshold of the mismatch is determined to be $40 \mathrm{~W} / \mathrm{m}^{2}$. If the difference is less than 40 , uniform irradiation is assumed. Sufficient information is not given on how this threshold is chosen and the threshold may vary depending on the panel structure.

Murtaza et al [13] uses multiples of open circuit voltage (0.8 $V_{o c}$ ) model that originates from the assumption that the local peaks, under partial shading condition occur at multiples of $\mathrm{V}_{\mathrm{oc}}$ The advantage is that tracking is confined only to a particular range. But the overall tracking speed is slow. A two-stage Global MPPT (GMPPT) method based on characteristic curves is reported in [14] in which $\mathrm{V}_{\mathrm{mpp}}$ is considered equal to voltage at Global MPP, $V_{\text {gmpp }}$ under shading condition, which may not be true. Li et al [15] propose a two-stage GMPPT method, which tracks an intermediate variable $(\beta)$ other than the power. Though no threshold parameter is required, it requires the generation of an equivalent PV string module for various shading patterns which can be tedious. Recent methods include Thermography based fault detection [16], which is useful to identify faults and visualize PV panel temperature. But thermal imaging faces the challenge of device aging and is not cost effective. In [17], flash test method is used to determine the fault detection based on I-V, P-V curves of solar panel. The drawback is that flash test is time consuming, and it requires the knowledge of PV datasheet. In [18], the partial shading detection algorithm is based on the geometric pattern of the shadow, and activation of bypass diodes depending on isolation. Though this curve scanning method gives a direct indication of the number of peaks in the I-V, P-V characteristics, but it is time-consuming. Also, this requires an already inbuilt reference, I-V curve to compare the actual I-V curve to detect shading. In [2], Artificial Neural Network (ANN) is used for partial shading detection and fault analysis of panel. Due to the number of cases considered by the ANN algorithm, it gives a real-time accuracy of $83 \%$ but the method become tedious in designing ANN algorithm under different system conditions. In [19], the PV reconfiguration under partial shading is not proved under practical situations. Even though drawback in shading is avoided by dispersing a shadow range of cells, it cannot be assured and is design specific. Qi et al [20] have provided a partial shading detection mechanism only in the left side of IV curve that is irrelevant under real-time PV setup. The power variation is considered as the parameter for shading detection which tries only to fit the curve and not very effective in detection.

A summary of different partial shading detection algorithms is presented in Table 1. This paper proposes a modified power loss method, which is tested both in simulation and in two realtime test beds. The proposed detection mechanism is accurate, as it directly taps the power loss from the solar panel, which is primarily due to the presence of blocking diodes. As a result, in this work the threshold value for detecting partial shading has been omitted. The paper is organized as follows: The power loss in different combinations of PV modules is presented in section 2. The proposed shading detection algorithm is presented in section 3 and the details of the experimental setup are provided in section 4 . The simulation and the experimental results are provided in section 5 and the conclusions are given in section 6 .

\section{Illustration of power loss in different combinations of PV modules under partial shading condition:}

\subsection{Four series connected solar PV modules}

To analyze the effects of partial shading on solar PV modules, four $300 \mathrm{~W}$ solar PV modules are modelled using a single diode equation and are simulated under uniform irradiance and partial shading condition. Initially all 4 modules are subjected to uniform irradiation of about $1000 \frac{\mathrm{W}}{\mathrm{m}^{2}}$ and then two modules are shaded with irradiation reduced to $500 \frac{\mathrm{W}}{\mathrm{m}^{2}}$ as shown in Figure 1 .

The electrical P-V and I-V characteristics are displayed in Figures 2(a) and 2(b). In these figures, three regions are mentioned as follows: Power (PEGMPP), Voltage (VEGMPP) and Current (IEGMPP) in Expected Global Maxima region, Power ( $\left.\mathrm{P}_{\mathrm{GMPP}}\right)$, Voltage $\left(\mathrm{V}_{\mathrm{GMPP}}\right)$ and Current $\left(\mathrm{I}_{\mathrm{GMPP}}\right)$ in Global Maxima region, Power $\left(\mathrm{P}_{\text {LMPP }}\right)$, Voltage $\left(\mathrm{V}_{\text {LMPP }}\right)$ and Current ( $\left.\mathrm{I}_{\text {LMPP }}\right)$ in Local maxima region. It is seen that between uniform and partial

Table 1. Review of Different Shading Detection Algorithms

\begin{tabular}{|c|c|c|c|c|}
\hline ALGORITHM & THRESHOLD & REAL-TIME & ACCURACY & LIMITATIONS \\
\hline $\begin{array}{c}\text { CURVE SCANNING } \\
{[18]}\end{array}$ & Yes & No & $\begin{array}{l}\text { Works for specific I-V,P-V } \\
\text { curves }\end{array}$ & $\begin{array}{c}\text { Time consuming, } \\
\text { prior knowledge of I- V,P-V } \\
\text { curves }\end{array}$ \\
\hline $\begin{array}{l}\text { THERMAL IMAGING } \\
{[16]}\end{array}$ & No & Yes & $\begin{array}{l}\text { Works for two shading } \\
\text { patterns }\end{array}$ & Cost \\
\hline $\begin{array}{l}\text { VOLTAGE MISMATCH } \\
\text { SCHEME [8] }\end{array}$ & Yes & Yes & Works for selected cases & $\begin{array}{c}\text { Requirement of voltage sensor for all } \\
\text { cells }\end{array}$ \\
\hline $\begin{array}{l}\text { DIRECT DUTY CYCLE } \\
\text { METHOD [9] }\end{array}$ & Yes & No & Works for select I-V,P-V curves & $\begin{array}{c}\text { Predicted duty cycle, } \\
\text { Approximations and empirical } \\
\text { threshold set }\end{array}$ \\
\hline ANN BASED [2] & Yes & Yes & $\begin{array}{c}\text { Works for uniform irradiation, contin } \\
\text { and rapidly changing } \\
\text { shadowing patterns }\end{array}$ & $\begin{array}{l}\text { Cost and training samples, } \\
\text { complexity of the system }\end{array}$ \\
\hline $\begin{array}{l}\text { IRRADIATION } \\
\text { VARIATION [12] }\end{array}$ & Yes & No & Works for select I-V,P-Curves & Empirical thresholds set \\
\hline L-ARRAY METHOD [1] & Yes & Yes & $\begin{array}{l}\text { Specific to geographic location and } \\
\text { temperature conditions }\end{array}$ & Empirical thresholds set. \\
\hline $\begin{array}{c}\text { NORMALISED } \\
\text { DEVIATIONSCHEME } \\
{[4]}\end{array}$ & Yes & No & Works for select curves & $\begin{array}{l}\text { No theoretical basisfor threshold } \\
\text { values }\end{array}$ \\
\hline $\begin{array}{l}\text { STATE OF SHADING } \\
{[10]}\end{array}$ & Yes & No & $\begin{array}{l}\text { Works for limited number of } \\
\text { shading patterns }\end{array}$ & $\begin{array}{l}\text { Prior knowledge of shading } \\
\text { pattern }\end{array}$ \\
\hline
\end{tabular}




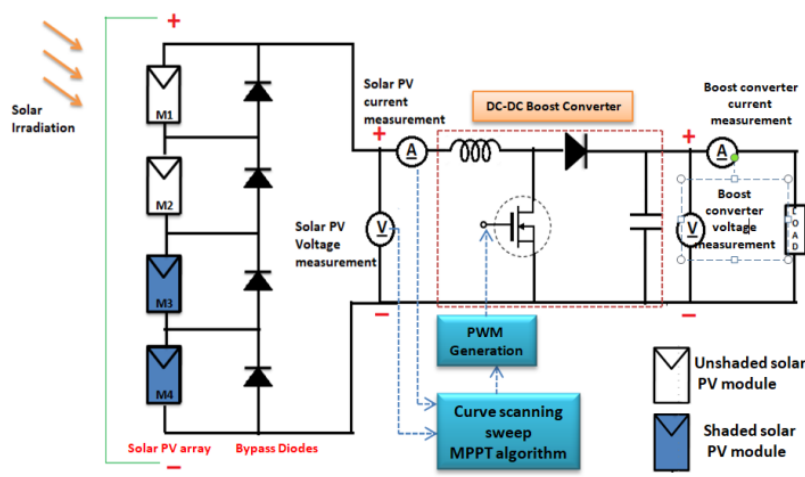

Fig.1. Schematic diagram of series connected solar PV module

shading conditions, the power extracted from the solar PV panel undergoes the maximum change. At uniform irradiation of about $1000 \frac{\mathrm{W}}{\mathrm{m}^{2}}$, it is seen that the general MPPT algorithm, identifies the MPP and it is about $1200 \mathrm{~W}$. Under partial shading conditions, due to non-generation of some cells, the entire power extracted from the solar PV setup drops to a maximum of 600 $\mathrm{W}$. This is visible from the difference in power generated at Local Maxima (LM) and Expected Global Maxima (EGM) as shown in Figure 2a. This shows that the effect of partial shading is not limited to the shaded cell alone, but rather expands its effect through the entire series connected module. This affects the efficiency of power generation as whole rather than just individual cells. The I-V characteristics under such conditions are plotted in Figure 2b. It is seen that there is a difference between the generated current at uniform irradiation condition and that of partial shading. Once a module is partially shaded, it is understood that the conventional algorithms get stuck at the local maxima point. It is seen that, generated currents at local and expected global maxima are different, although the voltage being the same. This is due to the fact, that once a solar module is shaded in series connection, power output is less than the expected power during uniform irradiation condition.

\subsection{Two series and Two parallel connected solar PV modules}

In this case, the arrangement of the solar PV modules is as shown in Figure 3. Under uniform and partial shading conditions, the electrical characteristics of the system are

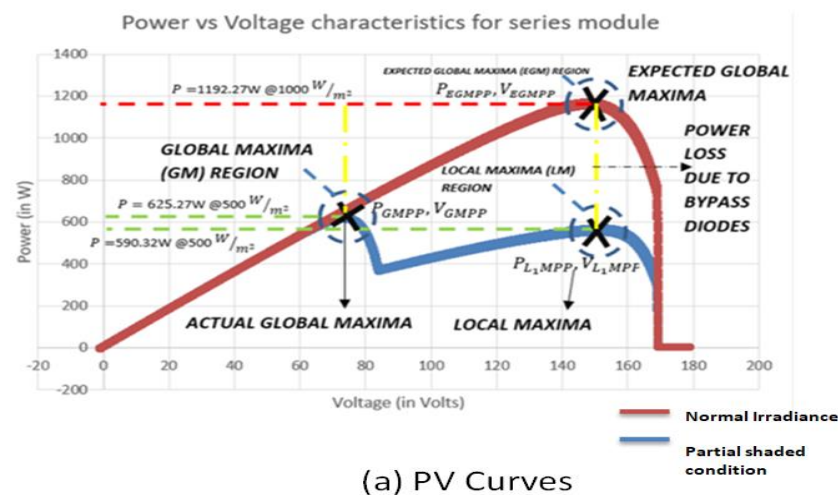

(a) PV Curves studied. The P-V characteristics of the solar PV system of series and parallel connection are shown in Figure 4. It is seen that under shading conditions, the shaded module's characteristics dominate the operation of the solar PV array. This is reflected in the solar PV array's voltage, which is closer to open circuit voltage of operation and the drawn current which is that generated by the shaded module. In other words, the effect of shading is spread rather than concentrated over the specified shaded region.

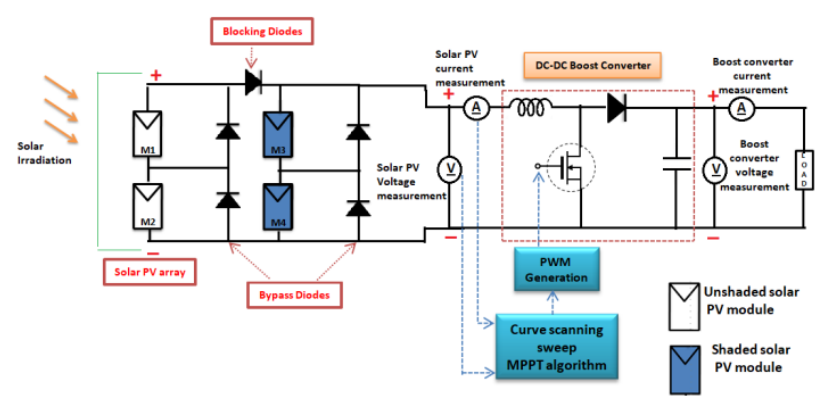

Fig. 3. Schematic diagram of series and parallel connected PV system

This leads to the fact that at uniform stable irradiation of 1000 $\frac{W}{m^{2}}$, the generated power from the PV array remains $1200 \mathrm{~W}$ whilst that obtained during shading conditions is only about $600 \mathrm{~W}$ at $500 \frac{\mathrm{W}}{\mathrm{m}^{2}}$. The region of operation of the PV array is in and around the LM region, resulting in huge power difference when compared with Expected Global Maxima region of operation.

The conclusions that can be drawn from the case studies are the following:

1) The effect of partial shading, due to the presence of bypass and blocking diodes affects power generation of the series and parallel connected module as a whole and is not centralized to only the shaded portion.

2) In a series connected module, the effect of shading ensures that the generated current is forced to a minimum value by a virtue of series connection of shaded cell to the unshaded ones. Thus, affecting the power generated from the solar

Current vs Voltage characteristics for series connected modules

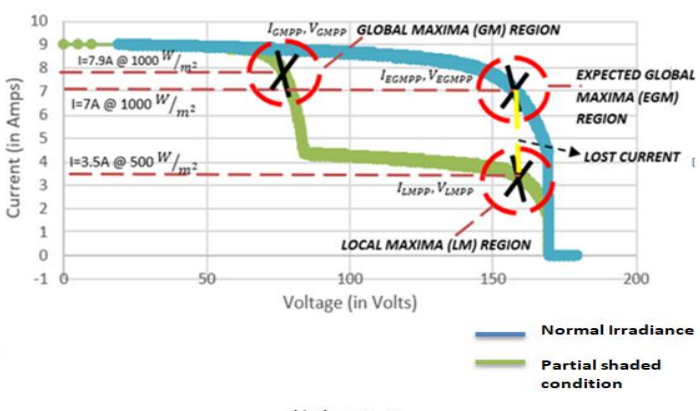

(b) IV Curves

Fig. 2 Power Voltage (PV) curves and Current Voltage (IV) curves for four $300 \mathrm{~W}$ series connected modules under uniform and partial shading conditions 


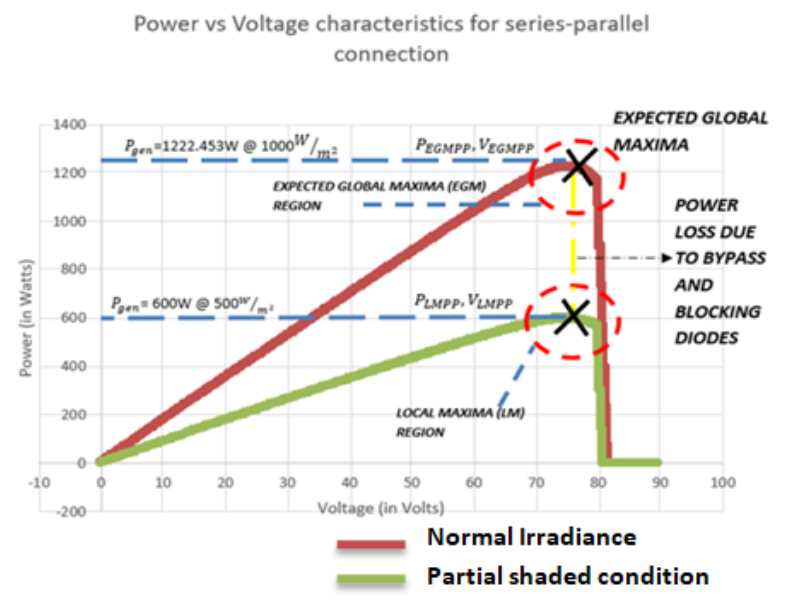

Fig. 4. P-V characteristics of series-parallel connected PV modules

PV module. Therefore, the operating point of the module is near to the Local Maxima, (LM) region than the Global Maxima, (GM) region. This is far from the Expected Global Maxima, (EGM) region and hence there is a huge power difference as shown in Figure 2(a).

3) In a parallel connected solar PV module using conventional MPPT algorithm, the effect of shading ensures that the voltage of the module, stays closer to the open circuit voltage of the setup, and hence forcing the current generated to be less. There is no occurrence of multiple maxima due to the operation of the blocking diodes, therefore there is no need to specify an actual GM region. Both LM and GM regions can be used interchangeably. In view of the context, the name LM region has been chosen. Thus, the operating point of the solar PV module remains at the LM region rather than the EGM region. Thus, the generated power is still very low in comparison to the expected power at Expected Global Maximum Power Point, (EGMPP) as shown in Figure 4.

4) It is clear from the above three conclusions, that in a given series/parallel connected setup, all measurable electrical parameters, solar current, voltage and power, undergo changes when there is a transition from uniform irradiation to partial shading condition. But there is a prominent difference in the electrical power drawn from the solar panel. Current and voltage parameters are not overlooked by doing so, but the changes in them are visible in a magnified manner when the power term is considered. Thereby, there is a need to take account of the loss in power due to shading effects.

\section{Proposed Modified Power Loss method based partial shading detection:}

It is known that a conclusive evidence of shading occurrence is the point where the shaded cells act as load to the generating cells. Deploying bypass diodes is essential to save the shaded cells from potential hotspots and in turn damage the surface of the solar PV panel. Activation of the bypass diodes upon occurrence of partial shading is a protective measure that safeguards the shaded cells and PV panel from potential failures and serves as a clear indication of the occurrence of partial shading depicted as flowchart in Figure 5. In this condition, it is safe to assume that zero current or rather minimal current is generated from the shaded cell. By virtue of the series combination, the actual power generated by a shaded series module drops. When a combination of series and parallel modules is chosen, it is seen that, both voltage and current are forced to a low value near the LM region as depicted in Figure 2. Upon comparison with the power to be generated under uniform irradiance conditions, it is seen that there is a huge difference. Formulating the power loss term under both series and/or parallel combinations is vital in determining the occurrence of shading, as it is directly influenced by the activation of the bypass and/or blocking diodes.

In Figure 3, it is depicted that two series modules are under shading condition and the rest are unshaded. Therefore, it is reasonable to assume that the unshaded modules (M1 and M2) receive an irradiance of G1 $\frac{W}{m^{2}}$ which is greater than the irradiance G2 $\frac{W}{m^{2}}$ received by the shaded modules (M3 and M4). Therefore, by the P-V characteristics of the modules and virtue of series connection, the combined voltage of the system is $V_{1}+V_{2}$, where $V_{1}$ and $V_{2}$ are the voltages of modules $M 1$ and M2, M3 and M4 respectively. Due to shading, it is understood that current I2, from modules M3 and M4 dominate, and hence the total power generated at the LM region of operation (G2 $\left.\frac{W}{m^{2}}\right)$ is $P_{a c t}=\left(V_{1}+V_{2}\right) I_{2}$. Whereas, the expected power to be generated at the EGM region of operation at irradiance G1 $\frac{W}{m^{2}}$ is,

$$
P_{g e n}=V_{1} I_{1}+V_{2} I_{2}
$$

Where $\mathrm{V}_{1}=\mathrm{V}_{2}=\frac{V_{E G M P P}}{N}$ and $\mathrm{I}_{1}=\mathrm{I}_{2}=I_{E G M P P}$ under uniform irradiation conditions and, VEGMPP and IEGMPP are Voltage and current at Expected Global Maximum Power Point.

Therefore, the power loss is computed as,

$$
\begin{gathered}
P_{\text {loss }}=P_{\text {gen }}-P_{\text {act }} \\
=\left(V_{1} I_{1}+V_{2} I_{2}\right)-\left(V_{1}+V_{2}\right) I_{2} \\
=V_{1} I_{1}+V_{2} I_{2}-V_{1} I_{2}-V_{2} I_{2} \\
=V_{1}\left(\mathrm{I}_{1}-\mathrm{I}_{2}\right)
\end{gathered}
$$

Considering the power loss term to be Larray, we see that the minimum value being 0 at EGM region and maximum being $V_{1} I_{1}$ at LM region. The power loss of $\mathrm{N}$ series modules can be calculated as follows:

The power that is expected to be generated at EGM region of operation (uniform irradiance level $\mathrm{G} 1 \mathrm{~W} / \mathrm{m}^{2}$ is,

$$
P_{\text {gen }}=V_{1} I_{1}+V_{2} I_{2}+\cdots+V_{N} I_{N}
$$

Assuming that module 2 is shaded, it is seen that actual power generated is

$$
P_{a c t}=\left(V_{1}+V_{2}+\cdots+V_{N}\right) I_{2}
$$




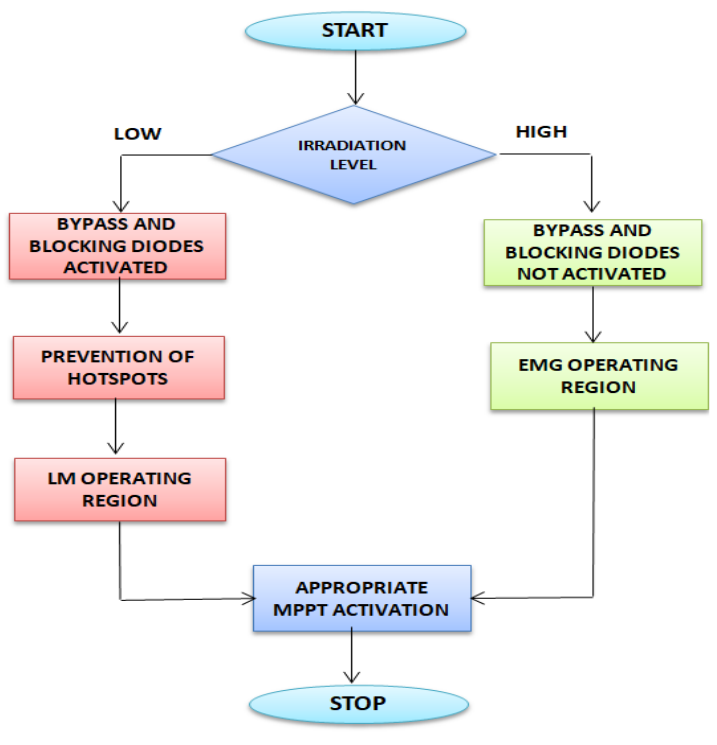

Fig. 5. Process flow in the occurrence of partial shading in solar PV panel

The power loss calculated from the solar PV array, at LM region of operation is,

$$
\begin{gathered}
P_{\text {loss }}=P_{\text {gen }}-P_{\text {act }} \\
P_{\text {loss }}=V_{1} I_{1}+V_{2} I_{2}+\cdots+V_{N} I_{N}-V_{1} I_{2}-V_{2} I_{2}-\cdots-V_{N} I_{2} \\
P_{\text {loss }}=V_{1}\left(I_{1}-I_{2}\right)+V_{3}\left(I_{3}-I_{2}\right)+\cdots+V_{N}\left(I_{N}-I_{2}\right)
\end{gathered}
$$

Analyzing the power difference term, in the LM region of operation during occurrence of partial shading the power loss is greater than the actual power generated which can be calculated as:

$$
\begin{gathered}
P_{\text {loss }}-P_{a c t}=V_{1}\left(I_{1}-I_{2}\right)+V_{3}\left(I_{3}-I_{2}\right)+\cdots+V_{N}\left(I_{N}-I_{2}\right)- \\
{\left[\left(V_{1}+V_{2}+\cdots+V_{N}\right) I_{2}\right]} \\
=V_{1} I_{1}-V_{1} I_{2}+V_{3} I_{3}-V_{3} I_{2}+\cdots+V_{N} I_{N}-V_{N} I_{2}-V_{1} I_{2}- \\
V_{2} I_{2}-\cdots-V_{N} I_{2} \\
=\left[V_{1} I_{1}+V_{3} I_{3}+\cdots+V_{N} I_{N}\right]-\left[V_{1} I_{2}+V_{2} I_{2}+\cdots+V_{N} I_{2}\right]>0
\end{gathered}
$$

The obtained difference is definitely greater than 0 because all expected currents in the EGM region of operation will definitely be greater than the generated current $I_{2}$ at LM region of operation. Hence, it is proved that $\mathrm{L}_{\text {array }}$ or $P_{\text {loss }}$ is greater than $P_{\text {act }}$ under partial shading conditions. The same can be extended to series and parallel combination of solar PV modules.

Let us assume a stand-alone solar PV setup, having $\mathrm{N}$ series modules and $\mathrm{M}$ such series modules in parallel. Whilst operating in the EGM region, the expected power to be generated by the setup is given as:

$$
P_{g e n}=V_{1} I_{1}+V_{2} I_{2}+\cdots+V_{M} I_{M}=\mathrm{M}(\mathrm{VI}),
$$

where, VI depicts the power generated by one module

$$
\begin{aligned}
& \text { At EGMPP, } V_{1}=V_{2}=\cdots=V_{M}=V_{E G M P P} \text { and } \\
& \qquad I_{1}=I_{2}=\cdots=I_{M}=\frac{I_{E G M P P}}{M}
\end{aligned}
$$

Assuming that row number 2 is shaded, either fully or partly, initially through operation of conventional MPPT algorithm, the operating point is in the $\mathrm{LM}$ region of the $\mathrm{P}-\mathrm{V}$ curve closer to the system's open circuit voltage. Thereby, it is observed that the shaded row, dominates the system's operating characteristics under shading conditions. This forces the generated power and voltage to be low and almost same as the power and voltage of row 2, $\left(\mathrm{P}_{2}\right.$ and $\left.\mathrm{V}_{2}\right)$. Therefore, the generated power from the PV module at the $\mathrm{LM}$ region of operation is

$$
P_{a c t}=V_{2}\left(I_{1}+I_{2}+\cdots+I_{M}\right)=\mathrm{M}\left(V_{2} I_{2}\right)
$$

The generated power loss at the LM region of operation during shading condition is given as:

$$
\begin{gathered}
P_{\text {loss }}=P_{\text {gen }}-P_{\text {act }} \\
P_{\text {loss }}=\mathrm{M}(\mathrm{VI})-\mathrm{M}\left(V_{2} I_{2}\right) \\
P_{\text {loss }}=\mathrm{M}\left(\mathrm{VI}-V_{2} I_{2}\right)
\end{gathered}
$$

Comparing power loss and actual power generated, we get,

$$
\begin{aligned}
P_{\text {loss }}-P_{a c t} & =\mathrm{M}\left(\mathrm{VI}-V_{2} I_{2}\right)-\mathrm{M}\left(V_{2} I_{2}\right) \\
& =\mathrm{M}\left(\mathrm{VI}-2 V_{2} I_{2}\right)
\end{aligned}
$$

The difference in power loss and actual power can be of positive, negative or 0 values. Under the cases of negative or zero values, which means that, the power generated from each of the series row has to be in their respective EGM region of operation, as only in such a case, the electrical parameters are not altered much which occurs during irradiance changing conditions. Even though load variation may exist, the difference would be such that, the operation region is not altered. Under partial shading conditions, the solution is positive which leads to the case where the operating points of the series connected modules is in the LM region. Hence, the equation that $P_{\text {loss }}>$ $P_{a c t}$ proves to be an accurate indicator for the detection of shading occurrence. The designed case studies and the obtained interferences therein do not limit the applicability of the power loss theorem method. Constraints like different patterns of shading, combinations of series parallel modelling can be introduced to check its validity. Although, the case studies introduced help in understanding the effects of partial shading and the resulting consequences.

The measured solar PV current and voltage are used to compute the expected power to be obtained at EGM region of operation at that specified irradiation level. This is known as expected power.

Expected power from panel $=P_{m}\left(\frac{G}{G_{0}}\right)$

Where $P_{m}$ is the Rated Panel power at $1000 \mathrm{~W} / \mathrm{m}^{2}$, G is the average value of monthly irradiation and $\mathrm{G}_{0}$ is $1000 \mathrm{~W} / \mathrm{m}^{2}$.The generated power at the current irradiation level, which may lead to either EGM region or LM region of operation is given by:

Generated power from panel $=V_{p v} * I_{p v}$

Where, $\mathrm{V}_{\mathrm{pv}}$ and $\mathrm{I}_{\mathrm{pv}}$ are the voltage and current at the PV panel. Power loss is then calculated as Expected power - Generated power, and if it is greater than the generated power, then the system is under shading condition else it is not shaded. 


$$
P_{m}\left(\frac{G}{G_{0}}\right)-V_{p v} * I_{p v}>V_{p v} * I_{p v}
$$

The proposed method has an advantage that, it does not depend on any empirical constant. In addition, the proposed power loss method is accurate even with average value of monthly irradiation which makes the algorithm very effective even in the absence of irradiation sensor. This gives the method an added advantage as it is cost effective and accurate even under different seasonal and weather conditions. The power loss method will remain accurate under different temperature conditions as well, as it only plays on the observed intrinsic electrical characteristics of the panel, rather than any external disturbances.

\section{Results and Discussion:}

The experimental setup for PV testbed is developed using National Instruments hardware and their interfacing software LabVIEW as shown in Figures 6. The PV real-time hardware setup is designed and tested under different conditions for the solar panel in the research lab of SRM Institute of Science and Technology, kattankulathur. The algorithm has been implemented in a real-time PV test bed as shown in Figure 6 for panel rating of $60 \mathrm{~W}$ ( 2 series of $30 \mathrm{~W}$ modules). The partial shading detection algorithm is embedded in a real-time operating system NI-cRIO 9081. The system has a very high processing speed in the order of $1.33 \mathrm{GHz}$ making it very accurate for measurement and control of solar panel parameters. The measurement system consists of two Virtual Benches (VB8012) for measurement of current from the $60 \mathrm{~W}$ solar panel and boost converter output voltage, and, generation of reference voltage for PWM generation and NI Elvis II+ for measuring panel voltage and a buck-boost converter of $60 \mathrm{~W}(30 \mathrm{~V}, 2 \mathrm{~A})$ was used for boosting the panel voltage. Boosted voltage is applied to an electrical load of $120 \Omega, 2.8 \mathrm{~A}$.

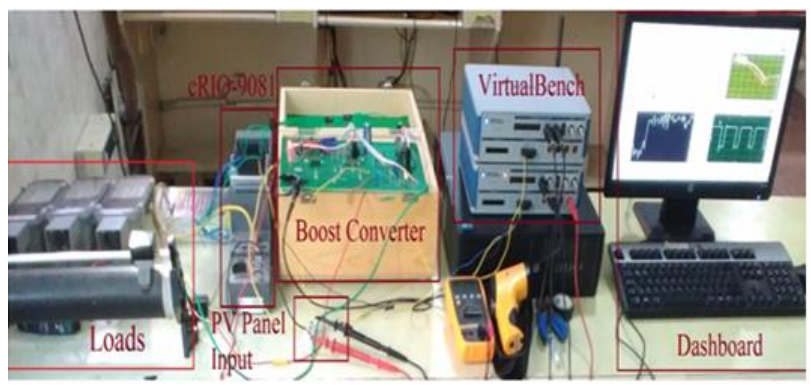

Fig. 6. Real time PV testbed setup at SRM Institute of Science and Technology

\subsection{Pattern 1: Emulating total shading of solar module, due} to cloud cover.

The power vs time for the real-time PV test bed with the shading detection algorithm is shown in Figure 7 for the shading pattern 1 . This shading pattern is used to replicate completely shaded conditions due to cloud cover directly above the solar module. In this case, the monthly average irradiance level is found to be $500 \mathrm{~W} / \mathrm{m}^{2}$. Under stable irradiation of $500 \mathrm{~W} / \mathrm{m}^{2}$, the PV module provides an output of $16.02 \mathrm{~W}$. There is a small variation in power output due to small changes in natural irradiation. This does not affect the partial shading detection algorithm, which continues to detect no occurrence of partial shading. During shading pattern 1, where most of the module is shaded as in Figure 7, the generated power drops to about $3 \mathrm{~W}$.
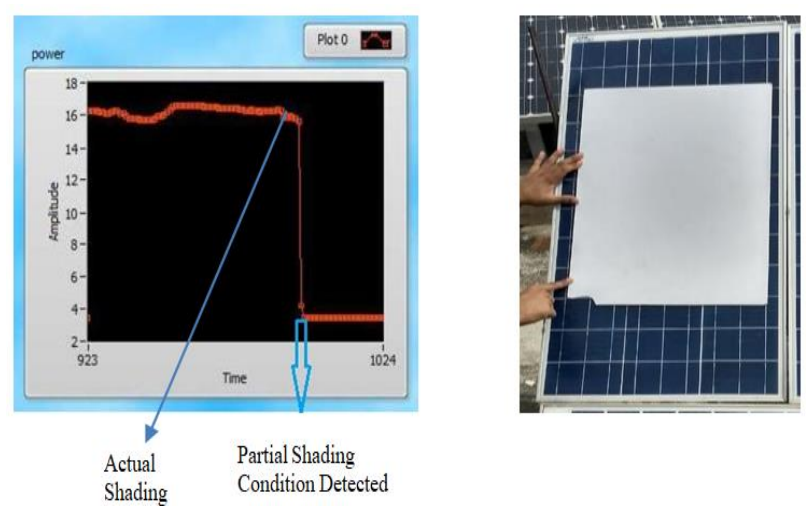

Fig. 7. Power Versus Time under shading pattern 1

5.2 Pattern 2: Emulating partial shading of solar module, due to cloud cover and shadow of buildings

The shading detection algorithm is then tested under high, stable irradiation conditions for the shading pattern 2 as shown in Figure 8. This pattern is chosen to replicate the shading pattern produced by some tall objects like buildings. This condition is also used for validation of the proposed algorithm because one cannot expect pattern 1 of shading to always occur. Under normal irradiation conditions of 500 $\mathrm{W} / \mathrm{m}^{2}$, the generated power from the solar PV module is about $16 \mathrm{~W}$ and the algorithm does not detect the occurrence of partial shading condition. Once pattern 2 of artificial shading is applied, the system generated power drops to $6.5 \mathrm{~W}$. As the string power loss is greater than the generated power, the proposed method detects the occurrence of partial shading condition accurately.
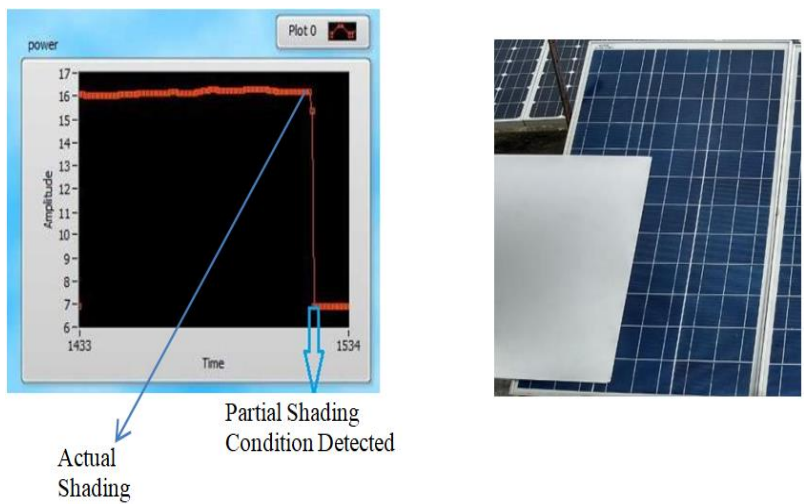

Fig. 8.Power Versus Time under shading pattern 2

The algorithm is validated for a run time of 2 hours (from 2 PM- 4 PM). It is subjected to constant, dynamic and irregular irradiance conditions as shown in Figure 9. The experimental dataset for the figure 9 is given in table 2. The algorithm accurately predicts the partial shading under actual shading conditions and does not produce erratic results under natural irradiation reduction. The current approximation method produces erratic results in this condition and often does not discriminate between actual shading and natural irradiation 
variation. The power loss method also fails in this case, due to the presence of a threshold value which is summarized in Table 3.

Table 2. Experimental dataset of the proposed method.

\begin{tabular}{|c|c|c|c|}
\hline S. No. & $\begin{array}{c}\text { Irradiance levels } \\
\left(\mathrm{W} / \mathrm{m}^{2}\right)\end{array}$ & Shading Detection & Normal / irradiation \\
\hline 1 & 575 & Yes & Normal \\
\hline 2 & 583 & No & Irradiation \\
\hline 3 & 600 & Yes & Normal \\
\hline 4 & 623 & Yes & Normal \\
\hline 5 & 876 & No & Irradiation \\
\hline 6 & 656 & No & Irradiation \\
\hline 7 & 344 & Yes & Normal \\
\hline 8 & 987 & No & Irradiation \\
\hline 9 & 786 & Yes & Normal \\
\hline 10 & 776 & Yes & Normal \\
\hline 11 & 976 & Yes & Normal \\
\hline 12 & 455 & Yes & Normal \\
\hline 13 & 608 & Yes & Normal \\
\hline 14 & 989 & No & Irradiation \\
\hline 15 & 587 & Yes & Normal \\
\hline 16 & 347 & Yes & Normal \\
\hline 17 & 786 & No & Irradiation \\
\hline 18 & 876 & No & Irradiation \\
\hline 19 & 654 & No & Irradiation \\
\hline 20 & 433 & Yes & Normal \\
\hline
\end{tabular}

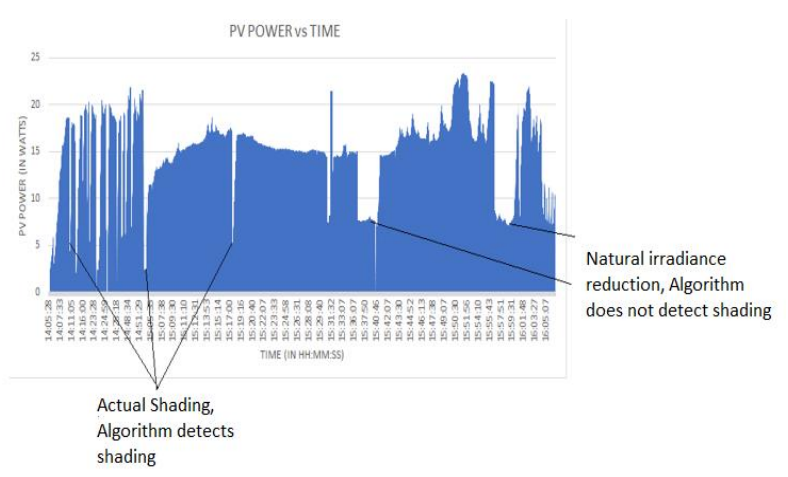

Fig.9. Partial shading condition detection under actual shading and natural irradiation reduction
Table 3. Comparison of Proposed method with existing detection methods

\begin{tabular}{|c|c|c|c|}
\hline $\begin{array}{c}\text { Comparison } \\
\text { Parameter }\end{array}$ & $\begin{array}{c}\text { Current } \\
\text { Approximation } \\
\text { Method }\end{array}$ & $\begin{array}{c}\text { Power Loss } \\
\text { Method }\end{array}$ & $\begin{array}{c}\text { Proposed } \\
\text { Power } \\
\text { Loss } \\
\text { Method }\end{array}$ \\
\hline $\begin{array}{c}\text { Accuracy (\%) } \\
\text { Standard } \\
\text { deviation }\end{array}$ & 0.46249 & 0.4858 & 0.17058 \\
\hline $\begin{array}{c}\text { Detection } \\
\text { during } \\
\text { irradiation } \\
\text { reduction }\end{array}$ & Erroneous & Erroneous & No \\
\hline $\begin{array}{c}\text { Detection } \\
\text { during natural } \\
\text { shading } \\
\text { condition }\end{array}$ & Erroneous & Erroneous & Yes \\
\hline $\begin{array}{c}\text { Detection time } \\
\text { Threshold } \\
\text { value }\end{array}$ & 0.00512 & Larray $>100 \mathrm{~W}$ & $\begin{array}{c}\text { Not } \\
\text { Essential }\end{array}$ \\
\hline
\end{tabular}

The Boolean graph depicting the performance of the proposed algorithm is shown in Figure 10. In this figure, logic 1 depicts shading detected, and logic 0 depicts no detection conditions. The proposed algorithm is checked continuously for two hours and it accurately predicts the actual partial shading condition.

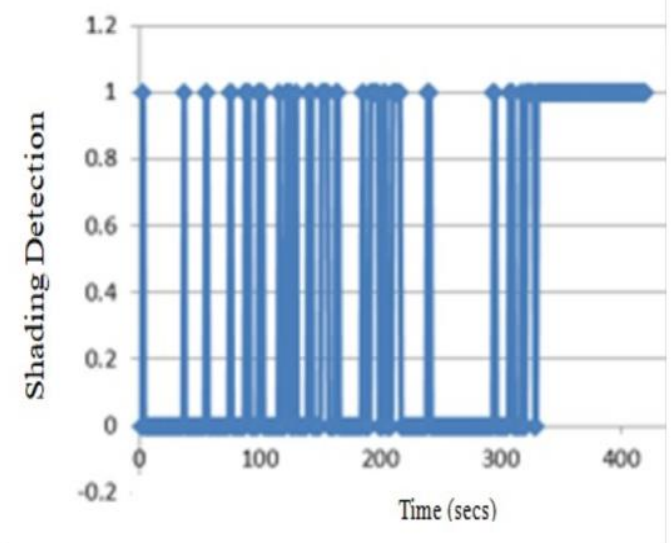

Fig.10. Boolean graph depicting the performance of proposed algorithm for pattern 2 .

\subsection{Statistical analysis of Experimental Data:}

As a measure of accuracy of the mathematical model developed for shading detection a statistical analysis was conducted using the ANOVA and F-Tests where, the experimental data was compared for variance and ANOVA value to prove the dependence of shading on $\mathrm{L}_{\text {array }}$ and the independence of shading on $\mathrm{P}_{\mathrm{pv}}$. These tests are conducted to study the correlation between the variables in play, in order to strengthen the validation of the power loss theorem. Null hypothesis assumes the three samples namely $\mathrm{P}_{\mathrm{pv}}$, Larray and shading belong to the same population. Firstly, one way ANOVA was conducted to find the significance of the three 
samples. It can be noted from the Table 4 that $\mathrm{f}$ (96.77) is greater

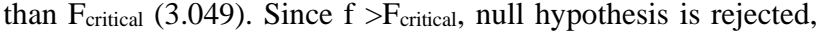
and it can be concluded that at least one of the three samples have significantly different means and thus belong to an entirely different population. To obtain further information on which sample is out of population, F-Test is conducted. It can be noted that $F_{\text {critical }}$ is greater than $f\left(F_{\text {critical }}<f\right)$ when shading and Larray are taken as samples. Hence, null hypothesis is accepted, and it can be concluded that $L_{\text {array }}$ and shading are dependent on each other. Furthermore, it implies that $\mathrm{P}_{\mathrm{pv}}$ and shading are not dependent which implies that proposed algorithm is accurate in detecting partial shading condition. Therefore, the power loss theorem clearly points out that, only power loss matters in any given condition of shading, and not just power generated from the solar panel. This is the guiding key point for the algorithm, which enables its success.

Table 4 Statistical analysis of Experimental Data

\begin{tabular}{|l|l|l|l|l|}
\hline \multicolumn{5}{|c|}{ ANOVA: Single Factor } \\
\hline Groups & Count & Sum & Average & Variance \\
\hline Shading & 58 & 27 & 0.4655 & 0.2532 \\
\hline Ppv & 58 & 3912.728 & 67.4608 & 1505.446 \\
\hline Larray & 58 & 3085.595 & 53.1999 & 733.500 \\
\hline
\end{tabular}

ANOVA Output Parameters

\begin{tabular}{|l|l|l|l|l|l|l|}
\hline $\begin{array}{l}\text { Source of } \\
\text { Variatio } \\
\text { n }\end{array}$ & $\begin{array}{l}\text { Sum of } \\
\text { Squares }\end{array}$ & df & $\begin{array}{l}\text { Mean } \\
\text { Square }\end{array}$ & F & $\begin{array}{l}\text { P- } \\
\text { value }\end{array}$ & Fcrit \\
\hline $\begin{array}{l}\text { Between } \\
\text { Groups }\end{array}$ & 144471.5 & 2 & $\begin{array}{l}72235.7 \\
3\end{array}$ & 96.7789 & $\begin{array}{l}7.76517 \\
\times 10^{-29}\end{array}$ & 3.0488 \\
\hline $\begin{array}{l}\text { Within } \\
\text { Groups }\end{array}$ & 127634.4 & 171 & 746.4 & -- & -- & - \\
\hline Total & 272105.8 & 173 & -- & -- & -- & - \\
\hline
\end{tabular}

\section{Conclusion and Future work:}

This paper proposes a modified power loss method for detecting the occurrence of partial shading. The proposed detection mechanism is accurate, as it directly taps the power loss from the solar panel, which is primarily due to the presence of blocking diodes. A threshold value, to detect partial shading is, therefore, eliminated in this work. The proposed algorithm detects that measured power from the panel and provides a detection accuracy of $97 \%$ under stable as well as dynamic irradiation conditions. The proposed partial shading detection algorithm is found to be more efficient in detecting partial shading under both uniform irradiance and dynamic irradiance conditions, without producing any erratic results in case of natural irradiation reduction. The proposed detection algorithm is compared with existing algorithms and promising results are produced. The modified power loss method is also validated theoretically, and experimental results are obtained in two different real-time testbeds which further emphasis the accuracy of the method in partial shading detection in solar panels. The algorithm can also be employed for fault analysis on the panel, to determine the exact causes of partial shading. The detection algorithm can be extended to find fill factor in fault detection, different shading patterns and reasons for the loss in power.

\section{Acknowledgement:}

The authors acknowledge the support provided by Department of Science and Technology-Science and Engineering Research Board-(DST SERB), New Delhi for the project "Optimal energy management system in shipboard microgrid with solar PV, (TAR/2018/000412) and National Institute of Ocean Technology for extending their support in providing research facilities.

\section{References}

(1) R. Hariharan, M. Chakkarapani, G. Saravanallango, and C. Nagamani, A Method to Detect Photovoltaic Array Faults and Partial Shading in PV Systems, IEEE Journal of Photovoltaics, 6(5), 2016, pp. 1278-1285.

(2) S. A. Rizzo and G. Scelba, ANN based MPPT method for rapidly variable shading conditions, Applied Energy, 145,2015, pp. 124- 132.

(3) Ramyar, H. Iman-Eini, and S. Farhangi, Global Maximum Power Point Tracking Method for Photovoltaic Arrays under Partial Shading Conditions, IEEE Transactions on Industrial Electronics, 64(4), 2017, pp 2855-2864.

(4) M. Miyatake, M. Veerachary, F.Toriumi, N. Fujii, and H. Ko, Maximum Power Point Tracking of Multiple Photovoltaic Arrays: A PSO Approach, IEEE Transactions on Aerospace and Electronic Systems, 47, 2011, pp. $367-$ 380 .

(5) J.Ahmed and Z. Salam, A Maximum Power Point Tracking (MPPT) for PV system using Cuckoo Search with partial shading capability, Applied Energy, 119, 2014, pp. 118-130.

(6) J. Young-Hyok, J. Doo-Yong, K. Jun-Gu, K. Jae-Hyung, L. TaeWon, and W. Chung- Yuen, A Real Maximum Power Point Tracking Method for Mismatching Compensation in PV Array Under Partially Shaded Conditions, IEEE Transactions on Power Electronics, 26, 2011, pp. 1001-1009.

(7) H. Renaudineau, A. Houari, J. P. Martin, S. Pierfederici, F. Meibody-Tabar, and Gerardin, A new approach in tracking maximum power under partially shaded conditions with consideration of converter losses, Solar Energy, 85, 2011,pp. 2580- 2588.

(8) C. Kai, T. Shulin, C. Yuhua, and B. Libing, An Improved MPPT Controller for Photovoltaic System Under Partial Shading Condition, IEEE Transactions on Sustainable Energy,5, 2014, pp. 978-985.

(9) N. Tat Luat and L. Kay-Soon, A Global Maximum Power Point Tracking Scheme Employing DIRECT Search Algorithm for Photovoltaic Systems, IEEE Transactions on Industrial Electronics, 57, 2010, pp. 3456-3467.

(10) M. H. Ali, A. Rabhi, A. El Hajjaji, and G. M. Tina, Real Time Fault Detection in Photovoltaic Systems, Energy Procedia, 111,2017, pp. 914-923.

(11) K. Sundareswaran, P. Sankar, P. S. R. Nayak, S. P. Simon, and S. Palani, Enhanced Energy Output from a PV System Under Partial Shaded Conditions Through Artificial Bee Colony, IEEE Transactions on Sustainable Energy, 6, 2015, pp. 198-209. 
(12) J. Ahmed, Z. Salam, An accurate method for MPPT to Detect the Partial Shading Occurrence in a PV System, IEEE Transactions on Industrial Informatics,13(5), 2017,pp.2151-2161.

(13) Murtaza, M. Chiaberge, F. Spertino, D. Boero, and M. De Giuseppe, A maximum power point tracking technique based on bypass diode mechanism for PV arrays under partial shading, Energy and Buildings, 73, 2014, pp. 1325.

(14) P. C. D. Goud, S. Member, and P. Samuel, GMPPT of Solar PV Array under Partial Shading Condition using LabVIEW FPGA, 2015, pp. 3411-3416.

(15) X. Li, H. Wen, Y. Hu, L. Jiang, and W. Xiao, Modified Beta Algorithm for GMPPT and Partial Shading Detection in Photovoltaic Systems, IEEE Transactions on Power Electronics, 33(3), 2018, pp. 2172-2186.

(16) Y.Hu, W.Cao, J.Wu, B.Ji and D.Holliday, ThermographyBased Virtual MPPT Scheme for Improving PV Energy Efficiency Under Partial Shading Conditions, IEEE Transactions on Power Electronics,29(11), 2014,pp.56675672.

(17) E. Garoudja, A. Chouder, K. Kara, and S. Silvestre, An enhanced machine learning based approach for failures detection and diagnosis of PV systems, Energy Conversion and Management.,151, 2017,pp.496-513.

(18) M. Bressan, Y. El Basri, A. G. Galeano, and C. Alonso, A shadow fault detection method based on the standard error analysis of I-V curves, Renewable Energy, 99, 2016, pp. $1181-1190$.

(19) N. Djilali and N. Djilali, PV array power output maximization under partial shading using new shifted PV array arrangements, Applied Energy, 187, 2017, pp. 326337.

(20) Qi,Y.Zhang,andY.Chen, Modeling and maximum power point tracking method for PV array under partial shaded conditions, Renewable Energy,66,2014,pp. 337-345.

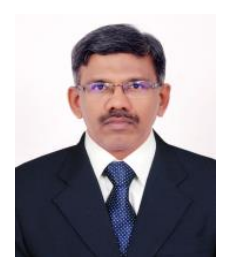

Dr. D. Devaraj completed his B.E and M.E in Electrical \& Electronics Engineering and Power System Engineering in the year 1992 and 1994, respectively, from Thiagarajar College of Engineering, Madurai. $\mathrm{He}$ has organized 2 International Conferences, 9 National Conferences, 6 seminars and conducted 16 workshops. He has authored 2 text books and co-authored 3 text books. He has published 126 papers in Journals and presented 250 papers in conferences. He is the Project Director of Power System Automation Group attached to TIFAC-CORE in Network Engineering which is sponsored by DST, Government of India. Currently, he is the principal investigator for the DST funded research project titled "Energy saving through IoT based building automation and Non-linear predictive controller". His research interest includes Power system optimization, Power system security, Voltage stability, Renewable Energy, Smart Grid, Evolutionary algorithms, Neural network, IoT and Data Mining. Presently, he is the Director-Academic \& Dean-SEET at Kalasalingam Academy of Research and Academy (KARE), Krishnankoil. He is a senior member of IEEE and actively involved in the student branch activities of KARE, since 2006.

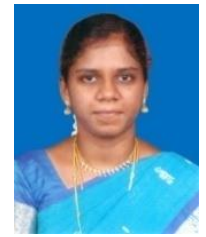

Dr. J. Preetha Roselyn received her B.E in Electrical and Electronics Engineering from Madras University, MS (By Research) from Anna University and Ph.D from SRM Institution of Science and Technology. Her area of interests includes voltage stability, soft computing applications in power systems, grid integration issues of renewable energy and smart metering infrastructure. She has published 20 papers in international journals and 15 papers in international conferences and 1 book. She is faculty mentor of SRM MTS student chapter, UK.

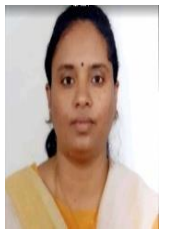

Mrs. C. Nithya received her B.E in Electrical and Electronics Engineering from BMS Institute of Science and Technology, M.Tech from SRM University. Currently she is pursuing Ph.D from SRM Institution of Science and Technology. Her area of interests includes voltage stability, grid integration issues of renewable energy.

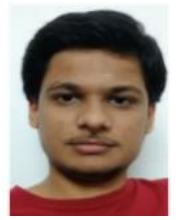

Mr. Pranav Chandran received his B.Tech in Electrical and Electronics Engineering from SRM Institution of Science and Technology. Currently he is pursuing MS in Power System Engineering, University of Washington, Seattle, US. He is the department topper in B.Tech for the academic year 2015-2019 with a percentage of $95 \%$. $\mathrm{He}$ has been a recipient of the annual SRM Merit scholarship for the academic year 2015-2019. His research interests include Power system, Solar PV systems and Renewable energy integration with the grid.

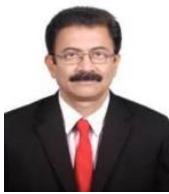

Dr. R. Venkatesan is a Scientist G and Group Head Ocean Observation Systems at the National Institute of Ocean Technology, Ministry of Earth Sciences, Chennai. He served as a Chair of IEEE India Council Ocean Engineering Society Chapter from 2016-2017 and is currently serving as a EXECOM member of IEEE OES India. He has 35 years of experience in the field of Ocean Technology. He earned his M.Tech. From Karnataka Regional Engineering College and $\mathrm{Ph} . \mathrm{D}$. degree from IISC, Bangalore and completed a course in marine environmental pollution and management and received his Doctor of Science DSc degree for his work on the topic moored ocean observatory. $\mathrm{He}$ is working on ocean observations and is also teaching ocean policy and ocean observation tools, as an adjunct faculty in three IITs. He is honored by receiving 12 awards including the UN Outstanding services certificate, MTS Lockheed Martin Award. He has established ocean observing system in Indian waters including for tsunami early warning and also in Svalbard in Arctic. He has authored 3 books, 105 papers in Journals including IEEE Journal, 250 invited talks and has field 6 patents to his credit. 